\title{
Lifestyle Behaviours and Dietary Habits in an Italian Sample of Premenopausal and Postmenopausal Women
}

\author{
Myriam Galfo $^{1}$, Fabrizia Maccati ${ }^{1}$, Francesca Melini ${ }^{1}$ \\ ${ }^{1}$ Council for Agricultural Research and Economics - Research Center on Food and Nutrition (CREA), Via \\ Ardeatina 546, Rome, 00178 Italy. \\ Corresponding Author: Myriam Galfo
}

DOI: https://doi.org/10.52403/ijhsr.20220301

\begin{abstract}
Objective: Menopause is the period when significant changes occur in women and influence their life quality. The aim of this study was to investigate lifestyle behaviours and dietary habits in an Italian sample of pre-menopausal and postmenopausal women.

Materials and Methods: A cross-sectional online survey was conducted May to July 2021 by online platforms. A total of 250 women (130 pre-menopausal and 120 post-menopausal) completed a selfreported questionnaire, comprising questions on demographic characteristics, anthropometrics data, lifestyle behaviours and dietary habits.

Results: Overweight/obesity prevalence was $22.4 \%$ with higher values of post-menopausal than premenopausal women (25.9\% vs $19.2 \%)$. Pre-menopausal women were slightly more physically active $(67.7 \%$ vs 65.8$)$, but with significantly lower percentages when exercised for $60+$ minutes $(36.2 \%$ vs $54.7 \%$; $\mathrm{p}=0.0130$ ). As to sedentary activities, higher and significant percentage of pre-menopausal women was found compared to post-menopausal women $(89.2 \%$ vs $67.5 \%$; $<<0.0001)$. Regarding the dietary habit of having breakfast regularly, a significantly higher percentage of post-menopausal than pre-menopausal women $(90.0 \%$ vs $80.0 \%)$ emerged. Multiple logistic regression model showed that smoking, physical activity and sleep duration affected significantly the ponderal status, whereas age, marital status, alcohol consumption, breakfast habit, and sweet consumption were not significant.

Conclusions: Not many differences in lifestyle and eating habits exist between pre-menopausal and post-menopausal women. The only significant differences relate to physical activity duration, sedentary behaviours and breakfast habit in favor of post-menopausal women. However, the prevalence of overweight/obesity was particularly linked to lifestyle behaviors such as smoking, sleep and physical activity in all participating women.
\end{abstract}

Keywords: Premenopausal women, postmenopausal women, lifestyle behaviours, dietary habits, overweight/obese

\section{INTRODUCTION}

Menopause is defined as the permanent loss of menstrual cycles and is a consequence of the cessation of ovarian activity. ${ }^{1}$ The age of menopause onset is genetically predetermined, and on average it involves women around the age of 50 years old, although it can vary in relation to eating habits and lifestyle, as well as to other environmental factors. ${ }^{2}$ Menopause is also one of the most critical stages of life in a woman. ${ }^{3}$

WHO defined postmenopausal women as those who naturally stopped menstruating a year before or those who stopped having periods as a result of some medical or surgical intervention. ${ }^{1}$ 
From menarche to menopause there are many biological changes in women's body and its effect on mind and health in totality needs to be examined carefully. ${ }^{4}$

The aging of society, the growing trend of a longer life expectancy and the longevity of women compared to men, make postmenopausal women one of the fastest growing sections of the population .5,6 Also, despite the rise of life expectancy, age of onset of menopause or end of menstruation has not changed, and women live for about 30 years (more than one third) of their lives in menopause or perimenopause. ${ }^{7}$

With a good nutrition and optimal intake of specific nutrients, together with lifestyle changes it is however possible to improve maintaining a healthy menopause. ${ }^{8}$ In fact, positive lifestyle changes, such as physical activity and dietary modifications, have clear benefits on many aspects of life in postmenopausal women, including physical and emotional changes, sleep, and cardiovascular health. ${ }^{9}$ Therefore, it is important to identify modifiable, lifestylerelated risk factors that can improve or prevent menopausal symptoms. ${ }^{10}$ Several risk factors for these symptoms, such as Body Mass Index (BMI), physical activity, smoking, and alcohol consumption, have been identified. ${ }^{11-13}$

Some studies have shown that there are no substantial changes due to the period of menopause, ${ }^{14-16}$ while other research studies have observed significant changes in the quality of life in postmenopausal women. ${ }^{17,18}$

In Italy, the average age of menopause is 51 years; however, the course of menopause symptoms can vary for each woman and often begins before menopause. Therefore, it is appropriate to identify the perimenopause complex period, in which some progressive mental and bodily changes may occur. ${ }^{19}$

The aim of this study was precisely to investigate lifestyle behaviours and dietary habits in an Italian sample of premenopausal and post-menopausal women.

\section{MATERIALS AND METHODS Study design and data collection}

The survey was conducted from May to July 2021, among an Italian sample of pre-menopausal and post-menopausal women, by using an online platform, accessible through any device with an Internet connection. The survey was disseminated through private social networks (e.g., WhatsApp, Twitter, Facebook). A total of 250 women completed the questionnaire. The survey was carried out in agreement with the Declaration of Helsinki (2000) and national and international regulations. All women were informed about the study and agreed to participate in the data collection. They also provided consent to the fact that these data were analyzed for research purposes only and possible publication, in accordance with current privacy regulations. Participants' personal information was anonymous to maintain and protect confidentiality. Given the anonymous nature of this survey and the fact it was carried out via the web, which does not allow any tracking of sensitive personal data, this study did not require the approval of the ethics committee. The final response database was downloaded as a Microsoft Excel sheet.

\section{Questionnaire}

The questionnaire was built ad hoc by using Google Form and consisted of personal data and anthropometrics information (such as questions on age, place of residence, marital status, household, selfreported weight and height, and education level); lifestyle factors (e.g., questions about smoke and alcohol habits, time sleep, type, frequency and duration of physical activity, time spent in sedentary activity such as reading, watching tv, using social networks); dietary habits information (such as questions on breakfast habits, daily consumption of certain foods as fruit and vegetable, sweet and eating between meals). 


\section{Anthropometric data}

Height and weight information obtained in the questionnaire was all selfreported by the respondents' women. BMI was calculated as the weight in kilograms divided by the square of the height in meters $\left(\mathrm{kg} / \mathrm{m}^{2}\right)$. Weight status was classified according to $\mathrm{WHO}{ }^{20}$ categories as follows: underweight (BMI < 18.5), normal weight (BMI between 18.5-24.9), overweight (BMI between 25 and 29.9) and obese (BMI $\geq$ 30).

\section{Statistical analysis}

The descriptive analyses were presented as means \pm standard deviations for quantitative variables, and as percentages for categorical variables. Chisquare test and T-tests were used to test for significant proportion and mean differences.

A multiple logistic regression model was employed to evaluate the association of selected lifestyle and dietary variables and overweight/obese ponderal status (dependent variable). Analyses were conducted with unadjusted and adjusted covariates.
For all the tests, $p$-values $<0.05$ were considered to be statistically significant. All statistical analyses were performed using MedCalc Software version 19.4.0 for Windows.

\section{RESULTS}

Characteristics of the study sample are shown in Table 1. Out of the 250 participants, $130 \quad(52 \%)$ were premenopausal and 120 (48\%) were postmenopausal women. The mean age was $42.4 \pm 16.5$ years $(28.4 \pm 9.6$ for premenopausal and $57.6 \pm 4.2$ for postmenopausal women) and BMI was 23.3 \pm 3.8 $\mathrm{kg} / \mathrm{m}^{2}$ with higher and significative percentage in post-menopausal than premenopausal women $(24.0 \pm 4.1$ vs $22.7 \pm 3.4$; $\mathrm{p}=0.0052$ ). The prevalence of overweight/ obesity was $22.4 \%$ with higher value of post-menopausal than pre-menopausal women $(25.9 \%$ vs $19.2 \%)$. Interestingly, there were $13 \%$ of underweight women with higher pre-menopausal than postmenopausal values (6.9\% vs $3.3 \%)$.

Table 1. Study sample parameters (means \pm standard deviation, $n$. and \%)

\begin{tabular}{|c|c|c|c|c|}
\hline Parameter & $\begin{array}{c}\text { All sample } \\
\mathrm{n}=250\end{array}$ & $\begin{array}{c}\text { Pre-menopausal women } \\
n=130(52 \%)\end{array}$ & $\begin{array}{c}\text { Post-menopausal women } \\
n=120(48 \%)\end{array}$ & $p$-value \\
\hline Age (years) & $42.4 \pm 16.5$ & $28.4 \pm 9.6$ & $57.6 \pm 4.2$ & $<0.0001^{a}$ \\
\hline Weight $(\mathrm{kg})$ & $62.8 \pm 10.5$ & $61.6 \pm 9.9$ & $64.1 \pm 10.9$ & $0.0531^{a}$ \\
\hline Height $(\mathrm{cm})$ & $163.8 \pm 8.7$ & $164.1 \pm 10.6$ & $163.6 \pm 6.1$ & $0.6760^{a}$ \\
\hline BMI & $23.3 \pm 3.8$ & $22.7 \pm 3.4$ & $24.0 \pm 4.1$ & $0.0052^{a}$ \\
\hline \multicolumn{5}{|l|}{ Nutritional status } \\
\hline Underweight & $13(5.2)$ & $9(6.9)$ & $4(3.3)$ & $0.3631^{b}$ \\
\hline Normal weight & $181(72.4)$ & $96(73.9)$ & $85(70.8)$ & \\
\hline Overweight & $38(15.2)$ & $18(13.8)$ & $20(16.7)$ & \\
\hline Obese & $18(7.2)$ & $7(5.4)$ & $11(9.2)$ & \\
\hline \multicolumn{5}{|l|}{ Education } \\
\hline Less than middle school & $10(4.0)$ & $4(3.1)$ & $6(5.0)$ & $<0.0001^{b}$ \\
\hline High School & $161(64.4)$ & $110(84.6)$ & $51(42.5)$ & \\
\hline University degree & $79(31.6)$ & $16(12.3)$ & $63(52.5)$ & \\
\hline Marital status & & & & \\
\hline Married/cohabiting & $117(46.8)$ & $44(33.8)$ & $73(60.8)$ & $<0.0001^{b}$ \\
\hline Divorced/widowed & $28(11.2)$ & $3(2.4)$ & $25(20.8)$ & \\
\hline Single & $105(42.0)$ & $83(63.8)$ & $22(18.4)$ & \\
\hline
\end{tabular}

In the total sample, the percentage of women who had attended high school was higher than the percentage of women who had university degree as well as than the percentage of those who had an education level lower than middle school (respectively
$64.4 \%$ vs $31.6 \%$ and $4.0 \%$ ). Compared to post-menopausal women, higher and significative values were observed for premenopausal women who had a high school level of education (84.6\% vs $42.5 \%$; $\mathrm{p}<0.0001)$, and percentage significantly 
Myriam Galfo et.al. Lifestyle behaviours and dietary habits in an Italian sample of premenopausal and postmenopausal women.

lower for university degree $(12.3 \%$ vs $52.5 \% ; \mathrm{p}<0.0001)$. In addition, there was significantly higher rate of married and cohabiting post-menopausal than premenopausal women $(60.8 \%$ vs $33.8 \%$; $\mathrm{p}<0.0001)$ and significantly lower of single and divorced/widowed (respectively, 18.4\% vs $63.8 \%$ and $20.8 \%$ vs 2.4 ; $\mathrm{p}<0.0001)$.

Lifestyle behaviours and dietary habits of total women' sample are given in Table 2.

Table 2 Lifestyle behaviours and dietary habits among total sample of women

\begin{tabular}{|c|c|c|}
\hline Variable & $\begin{array}{c}\text { Total sample } \\
n=250\end{array}$ & P value \\
\hline \multicolumn{3}{|l|}{ Smoking } \\
\hline Yes & $58(23.2)$ & $<0.0001^{*}$ \\
\hline No & $192(76.8)$ & \\
\hline \multicolumn{3}{|c|}{ Alcohol consumption } \\
\hline Everyday & $13(5.2)$ & $<0.0001^{*}$ \\
\hline Not everyday & $142(56.8)$ & \\
\hline Never & $95(38.8)$ & \\
\hline \multicolumn{3}{|l|}{ Sleep time } \\
\hline$\geq 7 \mathrm{~h}$ & $165(66.0)$ & $<0.0001^{*}$ \\
\hline$<7 \mathrm{~h}$ & $85(34.0)$ & \\
\hline \multicolumn{3}{|c|}{ Physical activity (PA) } \\
\hline Yes & $167(66.8)$ & $<0.0001^{*}$ \\
\hline No & $83(33.2)$ & \\
\hline \multicolumn{3}{|l|}{ PA duration } \\
\hline$\geq 60$ & $81(45.0)$ & $<0.0001^{*}$ \\
\hline $30-59 \mathrm{~min}$ & $80(44.4)$ & \\
\hline$<30$ & $19(10.6)$ & \\
\hline \multicolumn{3}{|l|}{ PA frequency } \\
\hline Everyday & $26(14.8)$ & $<0.0001^{*}$ \\
\hline 4-6 times/week & $46(26.1)$ & \\
\hline 2-3 times/week & $88(50.0)$ & \\
\hline 1 time/week & $16(9.1)$ & \\
\hline \multicolumn{3}{|l|}{ Sedentary activities } \\
\hline $\begin{array}{l}>3 \mathrm{~h} / \text { day } \\
\text { 2-3h/day }\end{array}$ & $\begin{array}{c}109(43.6) \\
88(35.2)\end{array}$ & $<0.0001^{*}$ \\
\hline 1h/day & 49 (19.6) & \\
\hline Never & $4(1.6)$ & \\
\hline $\begin{array}{l}\text { Breakfast habits } \\
\text { Yes } \\
\text { No }\end{array}$ & $\begin{array}{c}212(84.8) \\
38(15.2)\end{array}$ & $<0.0001^{*}$ \\
\hline \multicolumn{3}{|c|}{ Eating between meals } \\
\hline Yes & $181(72.4)$ & $<0.0001^{*}$ \\
\hline No & $69(27.6)$ & \\
\hline \multicolumn{3}{|c|}{ Fruit and vegetable consumption } \\
\hline$\geq 5$ servings/day & $22(8.8)$ & $<0.0001^{*}$ \\
\hline 2-4 servings/day & $160(64.0)$ & \\
\hline 1 serving/day & $56(22.4)$ & \\
\hline Nothing & $12(4.8)$ & \\
\hline \multicolumn{3}{|l|}{ Sweet consumption } \\
\hline$\geq 1$ serving/day & $85(34.0)$ & $<0.0001^{*}$ \\
\hline 4-6 servings/week & $15(6.0)$ & \\
\hline 1-3 servings/week & $126(50.4)$ & \\
\hline Never & $24(9.6)$ & \\
\hline \multicolumn{3}{|c|}{ Soft and sweet drinks consumption } \\
\hline$\geq 1$ serving/day & $17(6.8)$ & $<0.0001^{*}$ \\
\hline 4-6 servings/week & $9(3.6)$ & \\
\hline 1-3 servings/week & $90(36.0)$ & \\
\hline Never & $134(53.6)$ & \\
\hline
\end{tabular}

Table 3 Lifestyle behaviours and dietary habits in pre- and post-menopausal women

\begin{tabular}{|c|c|c|c|}
\hline Variable & $\begin{array}{c}\text { Pre- } \\
\text { menopausal } \\
n=130\end{array}$ & $\begin{array}{c}\text { Post- } \\
\text { menopausal } \\
n=120\end{array}$ & P value \\
\hline \multicolumn{4}{|l|}{ Smoking } \\
\hline Yes & $32(24.6)$ & $26(21.7)$ & 0.5818 \\
\hline No & $98(75.4)$ & $94(78.3)$ & \\
\hline \multicolumn{4}{|c|}{ Alcohol consumption } \\
\hline Yes & $78(60.0)$ & $77(64.2)$ & 0.4986 \\
\hline No & $52(40.0)$ & $43(35.8)$ & \\
\hline \multicolumn{4}{|l|}{ Sleep time } \\
\hline$\geq 7 \mathrm{~h}$ & $87(66.9)$ & $78(65.0)$ & 0.7489 \\
\hline$<7 \mathrm{~h}$ & $43(33.1)$ & $42(35.0)$ & \\
\hline \multicolumn{4}{|l|}{ Physical activity } \\
\hline Yes & $88(67.7)$ & $79(65.8)$ & 0.7556 \\
\hline No & $42(32.3)$ & $41(34.2)$ & \\
\hline$\geq 30 \mathrm{~min}$ & $90(95.7)$ & $71(82.6)$ & $0.0041^{*}$ \\
\hline$<30 \mathrm{~min}$ & $4(4.3)$ & $15(17.4)$ & \\
\hline$\geq 60 \mathrm{~min}$ & $34(36.2)$ & $47(54.7)$ & $0.0130 *$ \\
\hline$<60$ min & $60(63.8)$ & $39(45.3)$ & \\
\hline Every day & $11(11.7)$ & $15(18.3)$ & 0.2203 \\
\hline No every day & $83(88.3)$ & $67(81.7)$ & \\
\hline \multicolumn{4}{|c|}{ Sedentary activities } \\
\hline $\begin{array}{l}\geq 2 \mathrm{~h} / \text { day } \\
<2 \mathrm{~h} / \text { day }\end{array}$ & $\begin{array}{c}116(89.2) \\
14(10.8)\end{array}$ & $\begin{array}{l}81(67.5) \\
39(32.5)\end{array}$ & $<0.0001^{*}$ \\
\hline $\begin{array}{l}\text { Breakfast } \\
\text { habits } \\
\text { Yes } \\
\text { No } \\
\end{array}$ & $\begin{array}{c}104(80.0) \\
26(20.0) \\
\end{array}$ & $\begin{array}{c}108(90.0) \\
12(10.0)\end{array}$ & $0.0281^{*}$ \\
\hline \multicolumn{4}{|c|}{ Eating between meals } \\
\hline Yes & $97(74.6)$ & $84(70.0)$ & 0.4157 \\
\hline No & $33(25.4)$ & $36(30.0)$ & \\
\hline \multicolumn{4}{|c|}{ Fruit and vegetable consumption } \\
\hline $\begin{array}{l}\geq 5 \\
\text { servings/day }\end{array}$ & $11(8.5)$ & $11(9.2)$ & 0.8444 \\
\hline $\begin{array}{l}<5 \\
\text { servings/day }\end{array}$ & $119(91.5)$ & $109(90.8)$ & \\
\hline \multicolumn{4}{|c|}{ Sweet consumption } \\
\hline$\geq 1$ serving/day & $86(66.2)$ & $79(65.8)$ & 0.9575 \\
\hline$<1$ serving/day & $44(33.8)$ & $41(34.2)$ & \\
\hline \multicolumn{4}{|c|}{ Soft and sweet drinks consumption } \\
\hline$\geq 1$ serving/day & $9(6.9)$ & $8(6.7)$ & 0.9360 \\
\hline$<1$ serving/day & $121(93.1)$ & $112(93.3)$ & \\
\hline
\end{tabular}

Most of the sample did not smoke (about 77\%), 67\% did physical activity (50\% exercised 2-3 times a week, and 45\% for more than 60 minutes each time), $66 \%$ slept seven or more hours per night (as per international recommendations). However, it was also observed that $62 \%$ consumed alcohol and about $44 \%$ spent more than 3 hours per day in sedentary activities, such as watching TV, reading, cooking, using social networks.

Regarding dietary habits, $85 \%$ of the sample had breakfast every day, $72.4 \%$ was used to eating between meals, and $64 \%$ had 2-4 servings of fruit and vegetables per day (only $8.8 \%$ ate the WHO recommended 5 servings a day). 
Half of the participating women consumed sweets 1-3 times a week, while $34 \%$ consumed 1 or more times a day; about $54 \%$ did not consume soft and sweet drinks. All p-values of lifestyle and dietary habits variables were statistically significant.

Table 3 shows the differences in lifestyle behaviours and in food habits between pre-menopausal and postmenopausal women. It was observed that pre-menopausal women were slightly more physically active $(67.7 \%$ vs 65.8$)$ and with significantly higher percentages when exercised each time for 30 and more minutes $(95.7 \%$ vs $82.6 \%$; p $=0.0041)$ while they had significantly lower percentages when exercised each time for
60 and more minutes (36.2\% vs 54.7\%; $\mathrm{p}=0.0130)$ and for physical activity every day (11.7 vs 18.3) compared to postmenopausal women. Moreover, when participants spent two hours and more in sedentary activities, a higher and significant percentage of pre-menopausal was found compared to post-menopausal women $(89.2 \%$ vs $67.5 \%$; p <0.0001). On the other hand, there was a significantly higher percentage of post-menopausal than premenopausal women regarding the habit of having breakfast regularly $(90.0 \%$ vs $80.0 \%$ ). For all other lifestyle and dietary behaviours there were no significant differences between pre-menopausal and post-menopausal women.

Table 4. Odds ratios (OR) and 95\% Confidence Intervals (CI) from logistic regression analysis showing the association of ponderal status overweight/obese with selected behaviour variables ${ }^{\mathrm{a}}$

\begin{tabular}{|c|c|c|c|c|}
\hline \multirow[t]{2}{*}{ Independent variable } & \multicolumn{2}{|c|}{ Overweight/obese } & \multirow[b]{2}{*}{$\mathrm{aOR}(95 \% \mathrm{CI})$} & \multirow[b]{2}{*}{$p$-value } \\
\hline & cOR $(95 \% \mathrm{CI})$ & p-value & & \\
\hline \multicolumn{5}{|l|}{ Age } \\
\hline$\geq 50$ years vs $<50$ years & $1.45(0.80-2.63)$ & 0.2231 & $1.56(0.81-3.00)$ & 0.1835 \\
\hline \multicolumn{5}{|l|}{ Marital status } \\
\hline Married/cohabiting vs single & $1.08(0.59-1.95)$ & 0.8097 & $0.82(0.42-1.58)$ & 0.5511 \\
\hline \multicolumn{5}{|l|}{ Alcohol consumption } \\
\hline No vs yes & $1.43(0.78-2.61)$ & 0.2462 & $1.25(0.66-2.37)$ & 0.4901 \\
\hline \multicolumn{5}{|l|}{ Smoking } \\
\hline Yes vs no & $0.48(0.21-1.08)$ & 0.0774 & $0.36(0.15-0.88)$ & $0.0247 *$ \\
\hline \multicolumn{5}{|l|}{ Physical activity } \\
\hline No vs Yes & $2.08(1.13-3.83)$ & $0.0182 *$ & $1.97(1.02-3.81)$ & $0.0433^{*}$ \\
\hline \multicolumn{5}{|l|}{ Breakfast habits } \\
\hline No vs Yes & $2.04(0.97-4.32)$ & 0.0615 & $1.93(0.83-4.46)$ & 0.1249 \\
\hline \multicolumn{5}{|l|}{ Sweet consumption } \\
\hline$\geq 1$ serving/day vs $<$ serving/day & $0.72(0.38-1.39)$ & 0.3315 & $0.74(0.37-1.47)$ & 0.3906 \\
\hline \multicolumn{5}{|l|}{ Sleep time } \\
\hline$<7$ hours vs $\geq 7$ hours & $1.98(1.08-3.64)$ & $0.0273 *$ & $2.01(1.06-3.83)$ & $0.0333 *$ \\
\hline
\end{tabular}

Crude and adjusted odd ratios for lifestyle and dietary factors associated with an overweight/obese ponderal status, obtained from a multiple regression model are shown in Table 4. Smoking, physical activity and sleep time had a significant effect on overweight/obese ponderal status, whereas age, marital status, alcohol consumption, breakfast habits, and sweet consumption had no significative association. The results show that women who were not physically active had a likely two-fold higher risk of being overweight/obese compared to those who exercised (aOR 1.97, 95\% CI 1.02-3.81; $\mathrm{p}=0.0433)$. The women who slept less than seven hours/night were about 2 times more likely to run the risk of having an overweight/obese status than those who slept 7 and more hours (aOR 2.01, 95\% CI 1.06-3.83; $\mathrm{p}=0.0333$ ). Moreover, it was observed that smokers had about half the risk of becoming overweight/obese compared to those who did not smoke (aOR $0.36,95 \%$ CI 0.15-0.88; $\mathrm{p}=0.0247$ ).

The remaining variables did not significantly affect the ponderal status of overweight and obesity.

\section{DISCUSSION}

This cross-sectional study examined lifestyle behaviours and dietary habits in an 
Italian sample of pre-menopausal and postmenopausal women. A few studies have been so far conducted on post-menopausal women and on differences between them and pre-menopausal women. However, the results they present rarely refer to the whole general population. Our results showed that the mean of BMI and prevalence of overweight/obesity of post-menopausal women were higher than those of premenopausal women. Similar findings have been observed by the study of Bhurosy and Jeewon, where the mean anthropometric values of waist circumference, waist hip ratio and BMI were significantly higher among post-menopausal women, ${ }^{21}$ and by the research study of Karunakaran and Urooj in which post-menopausal women had a significantly higher mean BMI compared with pre-menopausal women. ${ }^{22} \mathrm{~A}$ similar trend of results has been reported by other studies. $^{23,24}$

Regarding physical activity, it was observed that post-menopausal women are more prone to sedentary habits and loss of fitness in comparison with pre-menopausal women. This sedentary lifestyle leads to deterioration of health and lower quality of life. ${ }^{25}$ It is known that physical activity for adult health, according to international recommendations, ${ }^{26}$ includes all physical activity carried out in leisure or recreational time, such as frequent walking, jogging, cycling, and doing physical exercises. These recommendations suggest getting at least 150 minutes per week of moderate-intensity aerobic activity or at least 75 minutes of vigorous activity a week or an equivalent combination of moderate and vigorous activity. For additional health benefits, adults should increase their moderateintensity physical activity to 300 minutes per week or engage in 150 minutes of vigorous activity per week, or an equivalent combination of the two. ${ }^{26}$ The current study found that post-menopausal women were slightly less physically active and with lower percentages when exercised each time for 30 minutes and more, but at the same time they had significantly higher rates when exercising for 60 minutes and more each time. Increased motivation for lifestyle changes during the menopausal period could explain this increasing physical activity. Another explanation could be that postmenopausal women probably have more leisure time to devote to physical activity than pre-menopausal women. Our results are in line with previous studies showing that in leisure time peri- and postmenopausal women had mostly high physical activity levels, while premenopausal women had low physical activity levels. ${ }^{27}$ Similar findings have been reported also in other studies. ${ }^{28}$

From the current study it was observed that postmenopausal women spend much less time in sedentary activities, such as reading, watching TV, using various social networks, compared to premenopausal women. This is because younger women spend a lot of time using particularly social networks than older women. Conversely, other studies reported that old-aged women were more likely to increase time spent in sedentary activities because of their higher rate of retirement, compared to younger women. ${ }^{29}$ Also, Duval and colleagues observed that during the menopausal transition women tend to shift to a more sedentary lifestyle. ${ }^{30}$

Regarding dietary habits, the results of this study showed that there were no significant differences between premenopausal and post-menopausal women excluding the breakfast habit. In fact, the results reported that there was a significantly higher percentage of postmenopausal women having breakfast daily than pre-menopausal women. Older women seem to be more attentive to healthy eating habits, such as having breakfast daily.

From multiple logistic regression model, it was observed that smoking, physical activity and sleep time had a significant effect on overweight/obese ponderal status of pre- and post-menopausal women. These results clearly show that smokers were less likely to be overweight or obese compared to women who had never 
smoked. Most studies have indicated that smokers on average have lower body weights, ${ }^{31-37}$ while a few have reported that smoking and body weight are positively correlated. $^{38,39}$ In our study, physical activity was inversely and significantly associated with overweight/obesity among pre- and post-menopausal women. Similar findings have been reported in the literature. $^{40-42}$ A 6-year follow-up study in 8352 postmenopausal women provided evidence for the protective impact of physical activity on weight development in older women. In fact, among participants aged 50-69 years, higher levels of physical activity were associated with less gain in fat mass, while, interestingly, in women aged 70-79 years, the loss in fat mass was not associated with physical activity. It was evidenced that efforts to encourage physical activity in post-menopausal women could be more effective at younger ages. ${ }^{43}$

In addition, a 13-year follow-up study in 34079 women found that participants aged 55-64 years with lowest physical activity gained significantly more weight than those with highest physical activity and this trend was not observed in women aged 65 years or older. ${ }^{44}$

Also, our results show that sleep duration was significantly correlated with overweight/obesity in pre-menopausal and post-menopausal women. In fact, women sleeping $<7$ hours/night were more likely to be overweight or obese than to women were used to sleep 7 or more hours. These findings support available descriptive literature that has documented the association between shorter sleep duration and risk for overweight and obesity. ${ }^{45-50}$ In a previous study on female population, it was observed that the influence of short sleep duration on accumulation of abdominal fat was more pronounced in women $<50$ years (most likely in pre-menopausal status). This finding indicates that the development of abdominal obesity may start early in life. ${ }^{51}$ The results of this study found support from the NHANES cohort, in which younger population, but not older than 50 years, showed an inverse association between reported short sleep duration and increased prevalence of overweight or obesity. ${ }^{52}$

The current study has however some limitations. First, the sample size of the survey is moderate; secondly, due to the cross-sectional design of this research, it is not possible to assess the causal relationship between lifestyle behaviours, dietary habits and pre- and post-menopausal women. Thirdly, because all information was collected by self-reported questionnaires, there is the possibility of information bias. Consequently, the findings should be cautiously generalized to other populations of women.

\section{CONCLUSION}

In conclusion, this research found that there are not many differences in lifestyle and eating habits between pre- and post-menopausal women. The only significant differences are given by physical activity duration, sedentary behaviours, and the healthy habit of having breakfast daily in favor of post-menopausal women who thus seem more virtuous. As for all women, however, we found that the prevalence of overweight/obesity was particularly linked to lifestyle behaviours, such as smoking, sleep time and physical activity.

A future longitudinal study design on a larger sample of women will be needed to further investigate these findings.

\section{Acknowledgements}

The authors gratefully thank who participated in this study.

\section{Funding source}

This research did not receive any specific grant from funding agencies in the public, commercial, or not-for-profit sectors.

\section{Conflict of interest statement}

The authors have no conflict of interest to declare.

Ethical Approval: Approved 


\section{REFERENCES}

1. World Health Organization. Research on the Menopause in the 1990s: Report of WHO Scientific Group. Geneva, 1996.

2. Sapre S, Thakur R. Lifestyle and dietary factors determine age at natural menopause. J Midlife Health 2014;5(1):3-5.

3. Rossouw JE, Anderson GL, Prentice RL. Risks and benefits of estrogen plus progestin in healthy postmenopausal women: Principal results from the women's health initiative randomized controlled trial. J Am Med Assoc. 2002;288:321-33.

4. Murthy, H. Health of women for $21 \mathrm{st}$ Century. Herald of Health 2003;19-21 pp.

5. Elavsky S, McAuley E. Physical activity, symptoms, esteem, and life satisfaction during menopause. Maturitas 2005;52(34):374-385.

6. Curl WW. MD Aging and Exercise: Are They Compatible in Women? Clinical Orthopaedics and Related Research 2000; 372:151-158.

7. Musker KM. Life patterns of women transitioning through menopause: A newman research study. Nurs Sci Q. 2008; 21:330-42.

8. Sharma S, Aggarwal N, Joshi B, Suri V, Badada S. Prevalence of metabolic syndrome in pre- and post-menopausal women: A prospective study from apex institute of North India. J Midlife Health 2016;7:169-74.

9. Anderson M. Effects of Diet and Exercise on Menopause 2014, https://pdfs.semanticscholar.org/fb56/b63d7 03cf3beda09e35522e65f069473b8ea.pdf

10. Herber-Gast G-CM, Mishra GD. Fruit, Mediterranean-style, and high-fat and -sugar diets are associated with the risk of night sweats and hot flushes in midlife: results from a prospective cohort study. Am J Clin Nutr. 2013;97:1092-1099.

11. Gold EB, Colvin A, Avis N, Bromberger J, Greendale GA, Powell L, Sternfeld B, Matthews K. Longitudinal analysis of the association between vasomotor symptoms and race/ethnicity across the menopausal transition: study of women's health across the nation. Am J Public Health 2006;96(7):1226-35.

12. Whitcomb BW, Whiteman MK, Langenberg P, Flaws JA, Romani WA. Physical activity and risk of hot flashes among women in midlife. J Womens Health 2007; 16:124133.

13. Leidy Sievert L, Makhlouf Obermeyer C, Price K. Determinants of hot flashes and night sweats. Ann Hum Bio 2006;33:4-16.

14. Brzyski RG, Medrona MA, Hyatt-Santos JM, Ross JS. Quality of life in low- income menopausal women attending primary care clinics. Fertil Steril 2001; 76(1): 44-50.

15. Dennerstein L, Dudley E, Guthrie J, BarretConner E. Life satisfaction, symptoms and the menopausal transition. Medscape Womens Health 2000;5(4): E4.

16. Ekstrom H, Hovelius B. Quality of life and hormone therapy in women before and after menopause. Scand J Prim Health Care 2000; 18:115-121.

17. Blumel JE, Castelo- Branco C, Binfa L, et al. Quality of life after the menopause: A population study. Maturitas 2000; 34(1):1723.

18. Fuh JL, Wang SJ, Lee SR, Lu SR, Juang KD. Quality of life and menopausal transition for middle-aged women on Kimmen Island. Qual Life Res. 2003;12:5361.

19. Vaccaro CM, Capozzi A, Ettore G, Bernorio R, Cagnacci A, Gambacciani M, Coletta V, Maffei S, Nappi RE, Scambia G, Viora E, Lello S. What women think about menopause: An Italian survey. Maturitas 2021;147:47-52.

20. World Health Organization. Obesity: preventing and managing the global epidemic 2000.

21. Bhurosy T. \& Jeewon R. Food habits, socioeconomic status and body mass index among premenopausal and postmenopausal women in Mauritius. J Hum Nutr Diet 2013;26(1): 114-122.

22. Karunakaran CG, Urooj A. Obesity status and lifestyle pattern of pre and postmenopausal urban-employed women of Mysore city, India. Adv Obes Weight Manag Control. 2017;6(2):47-57.

23. Javoor D, Malagi U, Naik R, Kasturiba. Nutritional Status of Menopausal Women: Karnataka. J Agric Sci. 2008;21(1):152-154.

24. Goswami AR, Ghanta P, Mandal N, Sengupta P. Nutritional and health status of pre-menopausal and post-menopausal women in rural bengalee population of mahishadal, west bengal, india. Int J Basic Appl Physiol. 2019; 8(1): 23-31. 
25. Sowers M, Zheng H, Tomey K, KarvonenGutierrez C, Jannausch M, Li X, et al. Changes in Body Composition in Women over Six Years at Midlife: Ovarian and Chronological Aging. J Clin Endocrinol Metab. 2007;92:895-901.

26. World Health Organization. Global Recommendations on Physical Activity for Health. Geneva: World Health Organization; 2010.

27. Dąbrowska-Galas, M, Dąbrowska, J, Ptaszkowski K, Plinta R. High Physical Activity Level May Reduce Menopausal Symptoms. Medicina 2019;55(8): 466.

28. Moilanen, J.M., Aalto, AM., Raitanen, J. Hemminki E, Aro AR, Luoto R. Physical activity and change in quality of life during menopause -an 8-year follow-up study. Health Qual Life Outcomes 2012;10:8.

29. Chomistek AK, Manson JE, Stefanick ML, Lu B, Sands-Lincoln M, Going SB, Garcia L, Allison MA, Sims ST, LaMonte MJ. Relationship of sedentary behavior and physical activity to incident cardiovascular disease: Results from the Women's Health Initiative. J. Am. Coll. Cardiol. 2013; 61:2346-2354.

30. Duval K, Prud'homme D, Rabasa-Lhoret R, Strychar I, Brochu M, Lavoie JM and Doucet E. Effects of the menopausal transition on energy expenditure: a MONET Group Study. Eur J Clin Nutr. 2013;67:407411.

31. Audrain-Mcgovern J, Benowitz NL. Cigarette smoking, nicotine, and body weight. Clin. Pharmacol. Ther. 2011;90(1):164-168.

32. Patel K, Hargreaves MK, Liu J, Schlundt D, Sanderson M, Matthews CE, Dewey CM, Kenerson D, Buchowski MS, Blot WJ. Relationship between smoking and obesity among women. Am J Health Behav. 2011;35(5):627-36.

33. Munafò MR, Tilling K, Ben-Shlomo Y. Smoking status and body mass index: a longitudinal study. Nicotine Tob Res. 2009;11(6):765-7.

34. Berlin I. Smoking-induced metabolic disorders: a review. Diabetes Metab. 2008; 34:307-314.

35. Chiolero A, Jacot-Sadowski I, Faeh D, Paccaud F, Cornuz J. Association of cigarettes smoked daily with obesity in a general adult population. Obesity 2007; 15:1311-1318.
36. Akbartabartoori M, Lean ME, Hankey CR. Relationships between cigarette smoking, body size and body shape. Int J Obes (Lond) 2005;29(2):236-43.

37. Canoy D, Wareham N, Luben R, et al. Cigarette smoking and fat distribution in 21,828 British men and women: a population-based study. Obes Res. 2005; 13:1466-1475.

38. Healton CG, Vallone D, Mc Causland KL, Xiao H, Green MP. Smoking, obesity, and their co-occurrence in the United States: cross sectional analysis. BMJ 2006;333:2526.

39. Cooper TV, Klesges RC, Robinson LA, Zbikowski SM. A prospective evaluation of the relationships between smoking dosage and body mass index in an adolescent, biracial cohort. Addict Behaviors 2003; 28:501-512.

40. Cárdenas Fuentes G, Bawaked RA, Martínez González MÁ, Corella D, Subirana Cachinero I, Salas-Salvadó J, Estruch R, Serra-Majem L, Ros E, Lapetra Peralta J, Fiol M, Rekondo J, Gómez-Gracia E, Tur Marí JA, Pinto Sala X, Babio N, Ortega C, Martínez JA, Schröder $\mathrm{H}$. Association of physical activity with body mass index, waist circumference and incidence of obesity in older adults. Eur $\mathbf{J}$ Public Health 2018;28(5):944-950.

41. Britton KA, Lee IM, Wang L, Gaziano JM, Manson JE, Buring JE, Sesso HD. Physical activity and the risk of becoming overweight or obese in middle-aged and older women. Obesity 2012;20(5):1096103.

42. Dąbrowska J, Dąbrowska-Galas M, Naworska B, Wodarska M, Plinta R. The role of physical activity in preventing obesity in midlife women. Prz Menopauzalny 2015;14(1):13-19.

43. Sims ST, Kubo J, Desai M, Bea J, Beasley JM, Manson JE, Allison M, Seguin RA, Chen Z, Michael YL, Sullivan SD, Beresford S, Stefanick ML. Changes in physical activity and body composition in postmenopausal women over time. Med Sci Sports Exerc. 2013;45(8):1486-92.

44. Lee IM, Djoussé L, Sesso HD, Wang L, Buring JE. Physical activity and weight gain prevention. JAMA 2010;303(12):11731179.

45. Patel SR, Malhotra A, White DP, Gottlieb DJ, Hu FB. Association between Reduced 
Myriam Galfo et.al. Lifestyle behaviours and dietary habits in an Italian sample of premenopausal and postmenopausal women.

Sleep and Weight Gain in Women. Am J Epidemiol. 2006;164 (10):947-954.

46. Marshall NS, Glozier N, Grunstein RR. Is sleep duration related to obesity? A critical review of the epidemiological evidence. Sleep Med Rev. 2008;12:289-298.

47. Patel SR, Hu FB . Short sleep duration and weight gain: a systematic review. Obesity 2008; 16:643-653.

48. Taheri S, Lin L, Austin D, Young T, Mignot E. Short sleep duration is associated with reduced leptin, elevated ghrelin, and increased body mass index. PLoS Med. 2004;1: e62.

49. Knutson KL, Van Cauter E. Associations between sleep loss and increased risk of obesity and diabetes. Ann N Y Acad Sci. 2008;1129:287-304.

50. Thomson CA, Morrow KL, Flatt SW, Wertheim BC, Perfect MM, Ravia JJ, et al.
Relationship between sleep quality and quantity and weight loss in women participating in a weight-loss intervention trial. Obesity 2012;20:1419-25.

51. Theorell-Haglöw J, Berne C, Janson C, Sahlin C, Lindberg E. Associations between short sleep duration and central obesity in women. Sleep 2010;33(5):593-8.

52. Gangwisch JE, Malaspina D, Boden-Albala B, Heymsfield SB. Inadequate sleep as a risk factor for obesity: analyses of the NHANES I. Sleep 2005;28:1289-96

How to cite this article: Myriam Galfo, Fabrizia Maccati, Francesca Melini. Lifestyle behaviours and dietary habits in an Italian sample of premenopausal and postmenopausal women. Int $J$ Health Sci Res. 2022; 12(3):1-10. DOI: https://doi.org/10.52403/ijhsr.20220301 